\title{
Low nanomolar concentrations of Cucurbitacin-I induces G2/M phase arrest and apoptosis by perturbing redox homeostasis in gastric cancer cells in vitro and in vivo
}

\author{
C Deng ${ }^{1,5}$, B Zhang ${ }^{1,5}$, S Zhang ${ }^{1}$, C Duan ${ }^{1}$, Y Cao ${ }^{1}$, W Kang ${ }^{2}$, H Yan ${ }^{3}$, X Ding ${ }^{1}$, F Zhou ${ }^{1}$, L Wu ${ }^{1}$, G Duan ${ }^{1}$, S Shen ${ }^{1}$, G Xu ${ }^{1}$, W Zhang ${ }^{4}$, \\ M Chen ${ }^{1}$, S Huang ${ }^{1}, X$ Zhang ${ }^{1}, Y$ Lv ${ }^{1}$, T Ling $^{1}$, L Wang ${ }^{1}$ and X Zou ${ }^{*}, 1$
}

Cucurbitacin-I (Cu-I, also known as Elatericin B or JSI-124) is developed to inhibit constitutive and abnormal activation of STAT3 in many cancers, demonstrating a potent anticancer activity by targeting disruption of STAT3 function. Here, we for the first time systematically studied the underlying molecular mechanisms of $\mathrm{Cu}$-l-induced gastric cancer cell death both in vitro and in vivo. In our study, we show that Cu-I markedly inhibits gastric cancer cell growth by inducing G2/M phase cell cycle arrest and apoptosis at low nanomolar concentrations via a STAT3-independent mechanism. Notably, Cu-I significantly decreases intracellular GSH/GSSG ratio by inhibiting NRF2 pathway to break cellular redox homeostasis, and subsequently induces the expression of GADD45 $\alpha$ in a p53-independent manner, and activates JNK/p38 MAPK signaling. Interestingly, Cu-l-induced GADD45 $\alpha$ and JNK/p38 MAPK signaling form a positive feedback loop and can be reciprocally regulated by each other. Therefore, the present study provides new insights into the mechanisms of antitumor effects of $\mathrm{Cu}-\mathrm{I}$, supporting $\mathrm{Cu}-\mathrm{I}$ as an attractive therapeutic drug in gastric cancer by modulating the redox balance.

Cell Death and Disease (2016) 7, e2106; doi:10.1038/cddis.2016.13; published online 18 February 2016

Despite a steady decline in gastric cancer incidence and mortality in the majority of developed countries, it is currently one of the most common malignancies and a leading cause of cancer-related death worldwide, particularly in some countries with historically high incidence (China, Japan, and Korea). ${ }^{1,2}$ Most gastric cancer patients are diagnosed at advanced stages and thus may no longer be candidates for curative therapies. Chemotherapy using a number of different combinations of agents (that is, 5-Fluorouracil, Adriamycin, Cisplatin, and so on) has been the common treatment for gastric cancers patients. However, they provide limited benefits for patients at advanced stages due to the low response rate and high rate of multidrug resistance. ${ }^{3}$ Thus, there is clearly an urgent need to develop more efficacious therapeutics to treat advanced gastric cancers.

Cucurbitacin-I (Cu-I), also known as Elatericin B or JSI-124, was originally identified to be a potent selective inhibitor of the Janus kinase 2/signal transducer and activator of transcription 3 (JAK2/STAT3) signaling pathway with antiproliferative and antitumor properties. ${ }^{4-7}$ Upon inhibition of STAT3-dependent gene transcription, $\mathrm{Cu}$-I elicits antiproliferative effects in breast, glioma, head and neck squamous carcinoma, and lung cancer cells with activated STAT3 signaling. 4,6,8,9 However, the anticancer effect and underlying mechanism of $\mathrm{Cu}-\mathrm{I}$ in human gastric cancer is still elusive.

In the present study, we show that Cu-I markedly inhibits the growth of gastric cancer cell lines by inducing G2/M phase cell cycle arrest and apoptosis at low nanomolar concentrations. Interestingly, mechanistic analysis revealed that the effect of $\mathrm{Cu}-\mathrm{I}$ is independent of STAT3 signaling but rather involves the disruption of the balance between pro-oxidants (ROS generation) and antioxidants (mainly expressed by the GSH/GSSG ratio). Furthermore, to the best of our knowledge, we revealed for the first time that Cu-I could efficiently inhibit NRF2 and its downstream targets, whose main function is to modulate GSH generation. ${ }^{10}$ Finally, we confirmed our in vitro observations by showing profound antitumor activity of $\mathrm{Cu}$-I in a xenograft model with no apparent toxicity to the mice. Our findings collectively indicated that $\mathrm{Cu}-\mathrm{I}$ may become a potential therapeutic agent against human gastric cancer in the future.

\footnotetext{
${ }^{1}$ Department of Gastroenterology, Drum Tower Hospital, Medical School of Nanjing University, Jiangsu Province, China; ${ }^{2}$ Department of Anatomical and Cellular Pathology, State Key Laboratory in Oncology in South China, Prince of Wales Hospital, The Chinese University of Hong Kong, Hong Kong SAR, PR China; ${ }^{3}$ Department of Laboratory Medicine, Changhai Hospital, the Second Military Medical University, Shanghai, China and ${ }^{4}$ Department of General Surgery, Drum Tower Hospital, Medical School of Nanjing University, Jiangsu Province, China

*Corresponding author: XP Zou, Department of Gastroenterology, Drum Tower Hospital, Medical School of Nanjing University, Nanjing, Jiangsu Province 210000, China. Tel: +86 25 83106666; Fax: +86 25 83307115; E-mail: zouxiaoping795@ hotmail.com

${ }^{5}$ These authors contributed equally to this work.

Abbreviations: CDC2, cell division cycle gene 2; DCF-DA, 2',7'-dichlorofluorescein diacetate; GADD45 $\alpha$, growth arrest and DNA-damage-inducible protein 45 $\alpha$; GCLM, glutamate-cysteine ligase complex modifier subunit; GSH, reduced glutathione; GSSG, oxidized glutathione; G6PD, glucose-6-phosphate dehydrogenase; JNK, c-Jun NH2-terminal kinase; MAPK, mitogen-activated protein kinase; NAC, N-acetyl-L-cysteine; NRF2, nuclear factor erythroid 2-related factor 2; PARP, poly(ADP-ribose) polymerase; ROS, reactive oxygen species; STAT3, signal transducer and activator of transcription 3

Received 19.10.15; revised 06.1.16; accepted 07.1.16; Edited by A Stephanou
} 


\section{Results}

Low nanomolar concentrations of $\mathrm{Cu}-\mathrm{I}$ inhibits viability of human gastric cancer cells independent of its anti-STAT3 activity. AGS and HGC-27 cells were incubated in medium with $\mathrm{Cu}$-I for $24 \mathrm{~h}$ over a range of concentrations $(0,12.5,25$, $40,50,100$, and $200 \mathrm{nM})$. And the cell viability was evaluated by CCK-8 assay. Cu-I treatment inhibited proliferation of both cell lines in a dose-dependent manner. The $\mathrm{IC}_{50}$ values of $\mathrm{Cu}$-I, which were $\sim 97.4 \mathrm{nM}$ and $123 \mathrm{nM}$ in AGS and HGC-27 cell lines, respectively, were much lower than those reported in other type of cancer cells (Figure 1a). ${ }^{4,7}$ We next treated both cell lines with $100 \mathrm{nM}$ and $200 \mathrm{nM}$ of Cu-I over a course of $48 \mathrm{~h}$. The CCK-8 assay showed that Cu-I treatment generated a maximal inhibition of cell viability rapidly (as soon as 24 h, Figure 1b). Furthermore, Cu-I treatment almost completely inhibited the formation of AGS and HGC-27 cell colonies as determined by colony-formation assays (Figure 1c,Supplementary Figure 1a and 1b). Taken together, these data support a suppressive role for $\mathrm{Cu}-\mathrm{I}$, which might inhibit gastric cancer cell growth at low nanomolar concentrations.

A number of lines of evidence suggested the antitumorigenic activity of $\mathrm{Cu}-\mathrm{I}$ is mainly due to their propensity to inhibit JAK2/STAT3 signaling, ${ }^{4-7}$ an important oncogenic pathway constitutively activated in a number of cancers. ${ }^{11-13}$ Although both gastric cancer cell lines had constitutive activation of STAT3 compared with the human normal gastric epithelial cell line GES-1 (Figure 1d), there was no obvious inhibition of Tyr705 or Ser727 phosphorylation of STAT3 in both cell lines following $\mathrm{Cu}-\mathrm{I}$ treatment at concentrations of $100 \mathrm{nM}$, which is close to the value of $\mathrm{IC}_{50}$ and inhibits cell growth effectively, whereas a notable reduction of Tyr705 phosphorylation in AGS cells and a marginal Ser727 phosphorylation in HGC-27 cells treated with $200 \mathrm{nM}$ of Cu-I, respectively, were observed (Figure 1e), suggesting that phosphorylation of STAT3 may be dispensable for the inhibitory role of $\mathrm{Cu}-\mathrm{I}$. To further demonstrate that STAT3 pathway is not involved in cell growth inhibtion by $\mathrm{Cu}-\mathrm{I}$ treatment at low concentrations, we used three individual siRNAs to specifically knock down the endogenous expression of STAT3 in AGS cells (Supplementary Figure 1c), however, gene silencing of STAT3 failed to restore the $\mathrm{Cu}$-l-inhibited cell growth (Figure 1f). Collectively, these data indicate that the antitumorigenic activity of $\mathrm{Cu}$-I was independent of its anti-STAT3 activity in gastric cancer cell lines.

Cu-I leads to G2/M cell cycle arrest and apoptosis in gastric cancer cells via induction of GADD45a. To further study the inhibitory effect of $\mathrm{Cu}-\mathrm{I}$ on cell growth, we investigated the cell cycle distribution in both cell lines by flow cytometry. Cu-I treatment for $12 \mathrm{~h}$ significantly induced G2/M phase arrest in both cell lines (Figure 2a and Supplementary Figure 1d). Concordantly, the expression of CDK7, cyclin B1, and CDC2, which are known to regulate G2/M phase transition, were markedly reduced (Figure $2 b$ ). After $\sim 1 \mathrm{~h}$ exposure to $\mathrm{Cu}-\mathrm{I}$ at $100 \mathrm{nM}$, both cell lines became shrunken, round, detached, or even floated, suggesting the apoptotic events may be present (Supplementary Figure 1e). Thus, we used Annexin V/PI assay to evaluate whether Cu-I could induce apoptosis in gastric cancer cells. Treatment of both cell lines with $\mathrm{Cu}-\mathrm{I}$ for $12 \mathrm{~h}$ markedly increased apoptosis (Figure 2c and Supplementary Figure $1 \mathrm{f}$ ). Consistently, caspase-9, caspase-8, and caspase-3 as well as PARP cleavage were activated by $\mathrm{Cu}-\mathrm{I}$ in a dosedependent manner (Figure 2d). To further demonstrate the requirement of caspase activity for cell death induced by $\mathrm{Cu}-\mathrm{I}$, HGC-27 cells were treated with $100 \mathrm{nM} \mathrm{Cu-I}$ in the absence or presence of pan-caspase inhibitor (Z-VAD-FMK, $20 \mu \mathrm{M}$ ). As shown in Figure 2e, the activation of caspase-9, caspase8, and caspase-3 as well as PARP cleavage trigged by Cu-I was partially abrogated by Z-VAD-FMK. Subsequently, Annexin V/PI double staining demonstrated that pretreatment with Z-VAD-FMK apparently inhibited the apoptotic cell death induced by $\mathrm{Cu}$-I (Figure 2f). These data add further evidence for the inhibitory role of $\mathrm{Cu}-\mathrm{I}$ against gastric cancer.

GADD45 $a$ has a pivotal role in cellular stress responses and is implicated in DNA damage repair, G2/M cell cycle arrest, and apoptosis. ${ }^{14,15}$ GADD45a mRNA is downregulated in gastric cancer (Supplementary Figure 2a). Moreover, elevated GADD45a mRNA is associated with a better prognosis and improved survival for gastric cancer patients (Supplementary Figure 2b). These data suggest GADD45a may be a tumor suppressor gene in gastric cancer. Interestingly, Cu-I treatment induced GADD45a protein markedly in both cell lines (Figure 2g). We then determined whether Cu-I-G2/M arrest and apoptosis was mediated by GADD45a. By using siRNAtargeting GADD45a mRNA (Supplementary Figure 2c), we found GADD45a depletion partly attenuated G2/M arrest induced by $\mathrm{Cu}-\mathrm{I}$ and reversed $\mathrm{Cu}-\mathrm{I}$-inhibited cyclin $\mathrm{B} 1$ and CDC2 expression in AGS cells (Figures $2 \mathrm{~h}$ and $\mathrm{i}$ ). In addition, depletion of GADD45a partially attenuated Cu-l-induced caspase-3 and PARP cleavage (Figure 2i), suggesting the apoptosis was also compromised. Altogether, our data indicate that $\mathrm{Cu}$-I leads to G2/M cell cycle arrest and apoptosis in gastric cancer cells at least partially via induction of GADD45a.

Cu-I induces DNA damage and GADD45a expression through a p53-independent manner. Apoptotic cell death is always triggered by DNA damage via p53-dependent or -independent manners. ${ }^{16}$ Comet assay was thus conducted to determine whether $\mathrm{Cu}-\mathrm{I}$ induced DNA damage in gastric cancer cells. After $12 \mathrm{~h}$ treatment, the comet tail lengths were $150.0 \pm 35.0 \mu \mathrm{m}$ and $228.0 \pm 12.0 \mu \mathrm{m}$, respectively, which was longer than that of control group. After $24 \mathrm{~h}$ treatment, the comet tail lengths increased to $313.5 \pm 11.5 \mu \mathrm{m}$ and $361.0 \pm 11.0 \mu \mathrm{m}$, respectively, which were much longer than that of the control cells (Figure $3 a$ ). Meanwhile, increased of $\gamma \mathrm{H} 2 \mathrm{AX}$, an early sign of DNA damage, ${ }^{17}$ was also observed in both AGS (p53-wild type) and HGC-27 (p53-mutated) cell lines upon $\mathrm{Cu}-\mathrm{I}$ treatment (Figure $3 \mathrm{~b}$ ). These results collectively indicated that $\mathrm{Cu}-\mathrm{I}$ treatment could induce DNA damage in gastric cancer cells, regardless of their p53 status via a dose- and time-dependent manner.

GADD45a is a well-known p53-responsive stress protein. Our data, however, excluded the role of p53 in inducing GADD45a in gastric cancer cells following $\mathrm{Cu}$-I treatment. First, GADD45a protein is induced by $\mathrm{Cu}-\mathrm{I}$ in both AGS (p53-wild type) and HGC-27 (p53-mutated) cell lines 
a

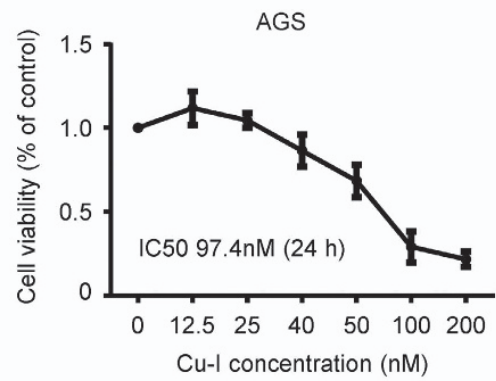

b

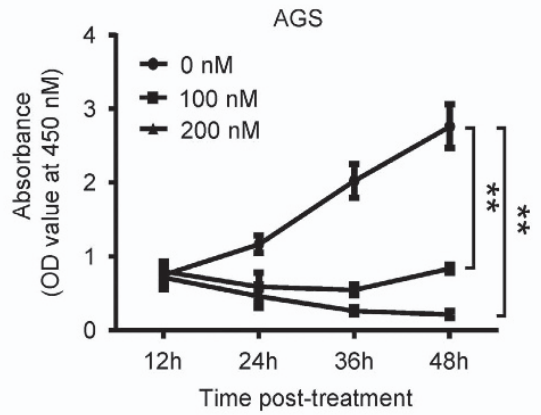

C

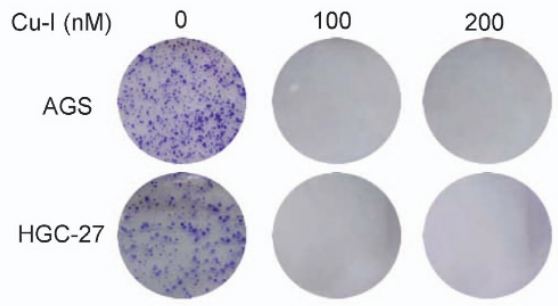

e

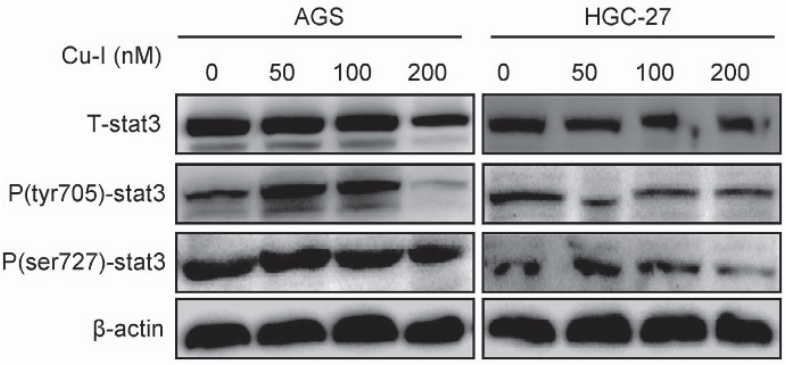

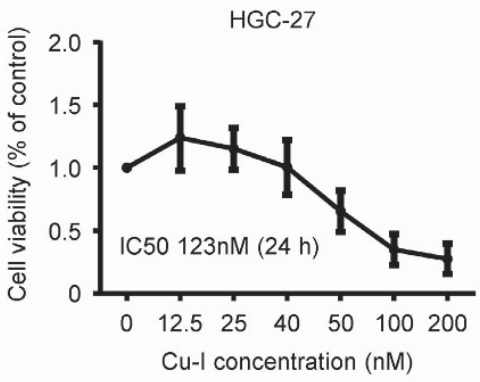

HGC-27

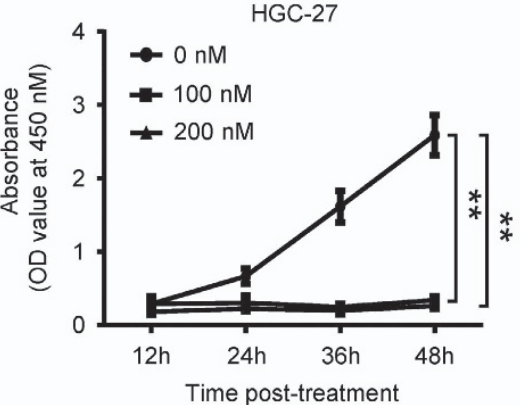

d

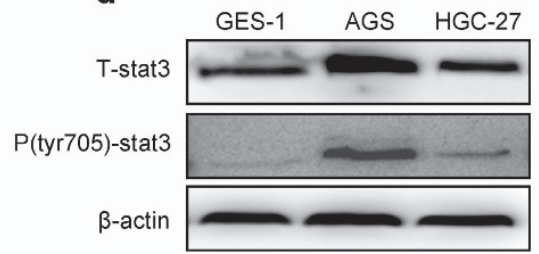

f

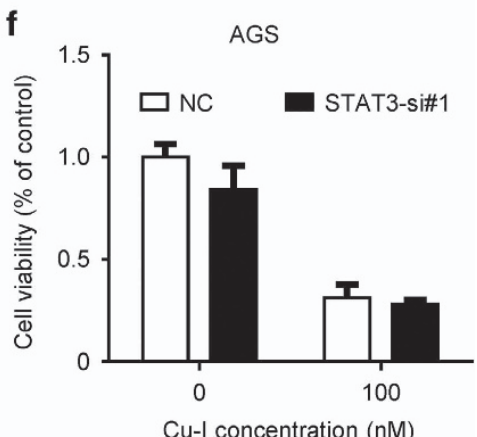

Figure 1 Cu-I inhibits viability of human gastric cancer cells independent of its anti-STAT3 activity at low nanomolar concentrations. (a) AGS and HGC-27 cells were treated with vehicle $(0.1 \%$ DMSO) or varying concentrations of $\mathrm{Cu}-\mathrm{I}$ for $24 \mathrm{~h}$ and assayed by CCK-8. Cell viability was calculated by the following formula: relative cell viability $=\left(\right.$ absorbance $_{450 \mathrm{~nm}}$ of treated group - absorbance $_{450 \mathrm{~nm}}$ of blank)/(absorbance ${ }_{450 \mathrm{~nm}}$ of control group - absorbance ${ }_{450 \mathrm{~nm}}$ of blank). (b) AGS and HGC-27 cells were treated with $100 \mathrm{nM}$ and $200 \mathrm{nM}$ of Cu-l over a course of $48 \mathrm{~h}$, relative absorbance at $450 \mathrm{nM}$ was analyzed to represent as time-dependent antitumor effect of Cu-I. Each data represent mean \pm S.D. of three independent experiments done in triplicates. ${ }^{*} P<0.05,{ }^{* *} P<0.01$. (c) Representative experiment of colony-formation assay of Cu-l-treated AGS and HGC-27 cells. Both cells were grown for 14 days treated with $100 \mathrm{nM}$ and $200 \mathrm{nM}$ of Cu-l, and stained with $0.5 \%$ crystal violet. (d) The protein levels of total and phosphorylated forms of STAT3 were analyzed by western blotting in GES-1 and AGS and HGC-27 cell lines. (e) Western blot analysis of total and phosphorylated STAT3 in AGS and HGC-27 cells untreated or treated with increasing concentration of Cu-I, respectively. (f) AGS cells were transfected with either negative control siRNA or STAT3-sil\#1 for $48 \mathrm{~h}$, and then followed by $100 \mathrm{nM} \mathrm{Cu-I}$ for another $24 \mathrm{~h}$. The cell viability was determined by using CCK-8

(Figure 2g). Second, Cu-I treatment does not activate p53 signaling because p53 itself, phosphorylated-p53, and its transcriptional targets (that is, p21 and puma) were not induced in AGS cells (Figure 3c). The luciferase activity of a reporter plasmid harboring a wild-type p53 response element showed virtually no responsiveness to treatment of AGS cells with Cu-I (Figure 3d). Third, GADD45a mRNA is induced in HGC-27 cells instead of AGS cells following Cu-I treatment (Figure 3e). These data suggest that GADD45a might be induced by $\mathrm{Cu}-\mathrm{I}$ through a p53-independent manner. 
Cu-I induces JNK/p38 MAPK activation in gastric cancer cells. It has been reported that activation of MAPK subfamilies by cucurbitacins could induce oxidative stress-

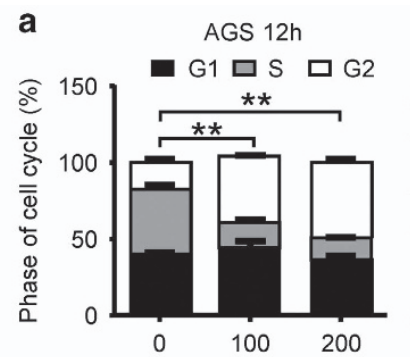

Cu-I concentration (nM)

\section{C}

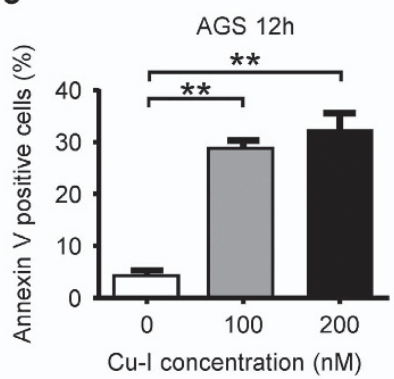

e

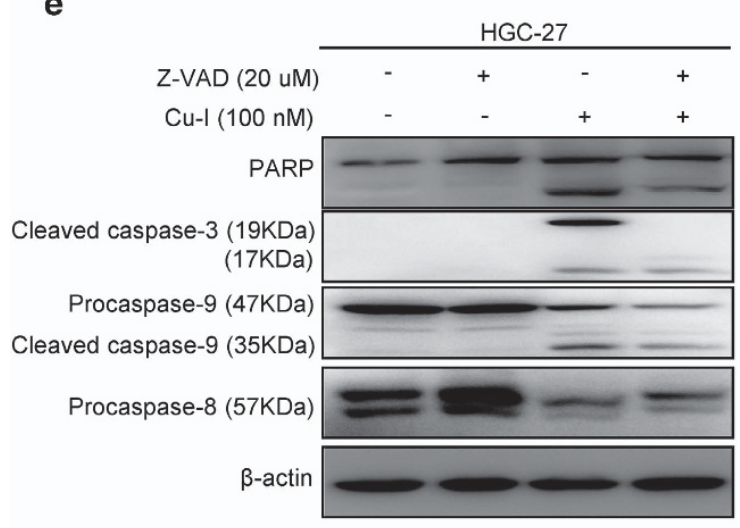

g

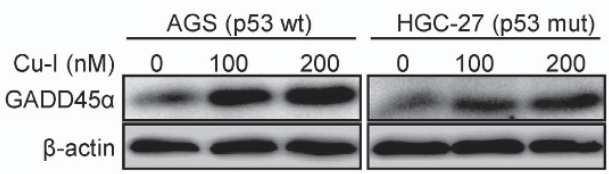

h

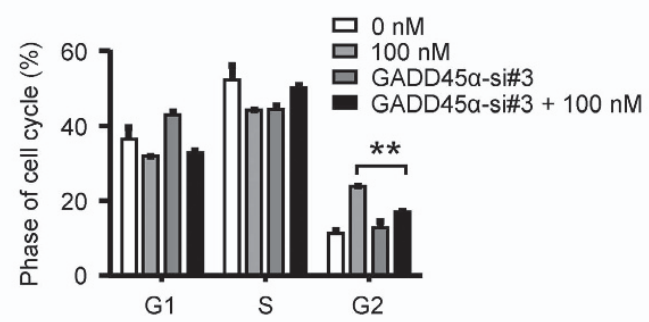

mediated cell death. ${ }^{18}$ To evaluate whether MAPKs activation was involved in inhibition of cell proliferation in gastric cancer cells treated with $\mathrm{Cu}-\mathrm{I}$, we examined the changes of two

b

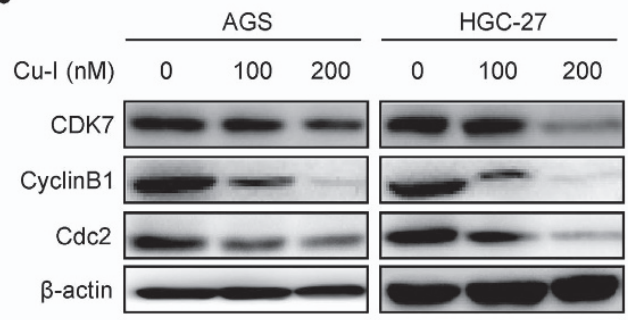

d

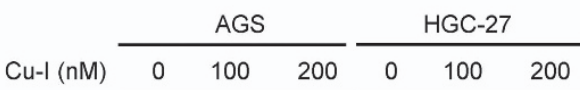

PARP $=\equiv$

Procaspase-3 (35KDa)

Cleaved caspase-3 (19KDa) (17KDa)

Procaspase-9 (47KDa) Cleaved caspase-9 (35KDa) Procaspase-8 (57KDa) $\beta$-actin
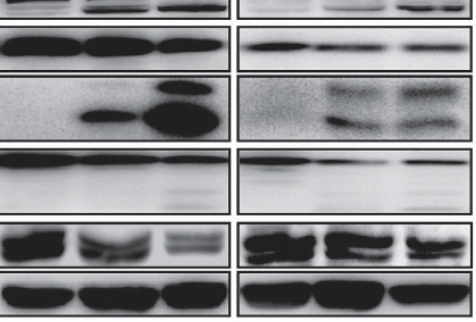

f

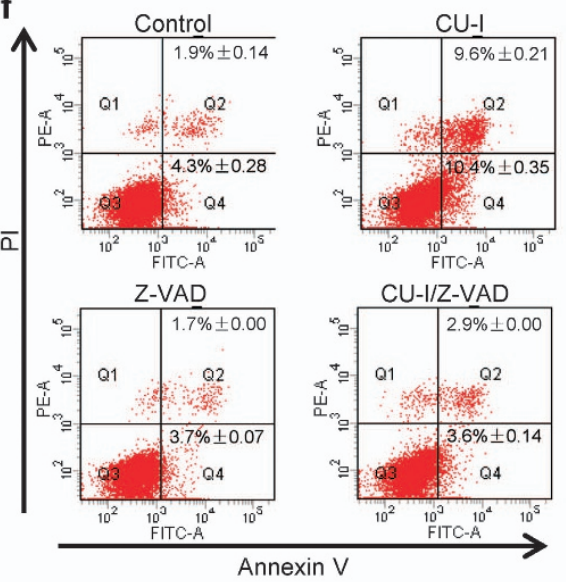

i Cu-I (100nM) $\frac{\text { NC-siRNA }}{-} \frac{\text { GADD45a-si\#3 }}{-} \frac{+}{-} \frac{+}{2}$

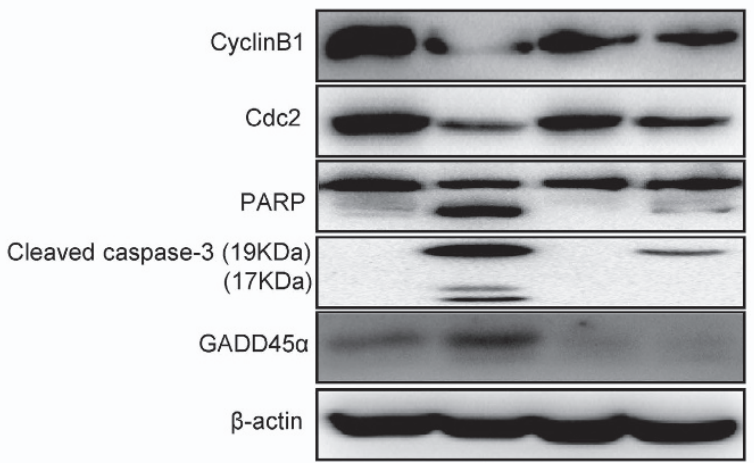


a

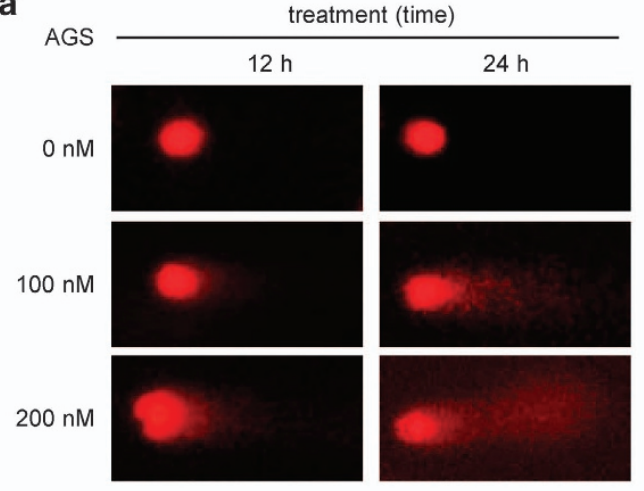

b
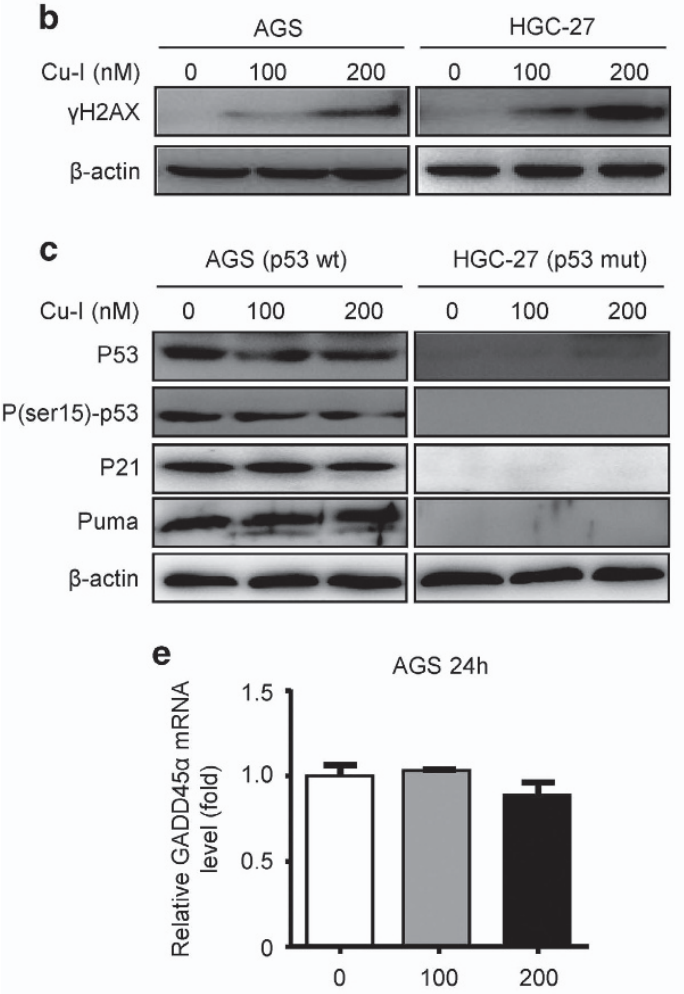

Cu-I concentration (nM)

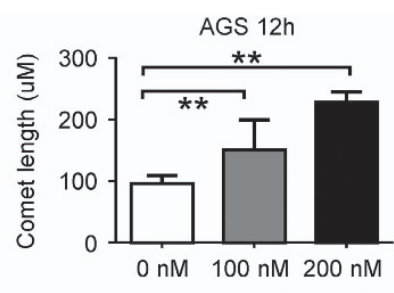

Cu-I concentration (nM)

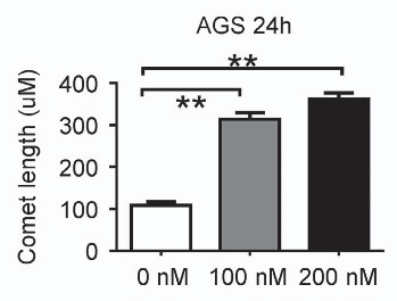

Cu-I concentration (nM)

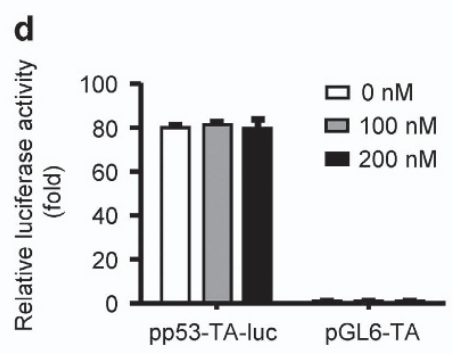

Figure 3 Cu-l induces DNA damage and GADD45 $\alpha$ expression through a p53-independent manner. (a) Typical SCGE pictures (left) of the control group, $100 \mathrm{nM}$ and $200 \mathrm{nM}$ treatment group for $12 \mathrm{~h}$ and $24 \mathrm{~h}$. Measurements were conducted in triplicate. ( $\times 400)$. (right) Quantitative analysis of comet tail lengths from the SCGE pictures. ${ }^{* \star} P<0.01$. (b) Western blotting analysis of the expression levels of $\gamma \mathrm{H} 2 \mathrm{AX}$. (c) Western blotting analysis of the expression levels of p53 itself, P(ser15)- p53 and its other transcriptional targets (p21 and puma) in both AGS and HGC-27 cells. (d) P53 transcription activity in Cu-l-treated AGS cells was evaluated by using p53 response element luciferase activity assay. (e) GADD45 $\alpha$ mRNA level in AGS and HGC-27 cells treated by $\mathrm{Cu}$-l for $24 \mathrm{~h}$ was assayed by quantitative real-time PCR. $\beta$-actin served as an internal control. ${ }^{* *} P<0.01$

Figure 2 Cu-I leads to G2/M cell cycle arrest and apoptosis in gastric cancer cells via induction of GADD45 $\alpha$. (a) Cell cycle analysis of AGS and HGC-27 cells after treatment with 0,100, $200 \mathrm{nM}$ Cu-l for $12 \mathrm{~h} .{ }^{\star} P<0.05,{ }^{* \star} P<0.01$. (b) The protein expression of CDK7, cyclin B1, and CDC2 in AGS and HGC-27 cells treated with 0, 100, $200 \mathrm{nM}$ Cu-l for $24 \mathrm{~h}$ was evaluated by western blotting. (c) Annexin V levels of AGS and HGC-27 cells after treatment with $0,100,200 \mathrm{nM}$ Cu-I for $12 \mathrm{~h}$ were assayed by flow cytometry. ${ }^{* *} P<0.01$. (d) Cleavage of caspase-9, caspase-8, caspase-3, and PARP was evaluated by western blotting in both cell lines after treatment with Cu-I for $24 \mathrm{~h}$. (e) HGC-27 cells were treated with $100 \mathrm{nM}$ Cu-I with or without pan-caspase inhibitor (Z-VAD-FMK, $20 \mu \mathrm{M}$ ) for $24 \mathrm{~h}$, then whole-cell lysates were separated by SDS-PAGE and reacted with indicated antibodies. (f) HGC-27 cells were treated as described above for $12 \mathrm{~h}$, Annexin V/PI double staining was assayed by flow cytometry. (g) Western blot analysis of Cu-Iinduced GADD45 $\alpha$ protein expression in AGS and HGC-27 cells. (h) AGS cells were transfected with either negative control siRNA or GADD45 $\alpha$-Si\#3 for $48 \mathrm{~h}$, and then followed by treatment of $100 \mathrm{nM}$ of $\mathrm{Cu}-\mathrm{I}$ for $12 \mathrm{~h}$, the percentage of phase of cell cycle was determined by flow cytometry. ** $P<0.01$, compared with Cu-l alone-treated group. (i) AGS cells were transfected with either negative control siRNA or GADD45 $\alpha$-si\#3 for $48 \mathrm{~h}$, and then followed by treatment of $100 \mathrm{nM}$ of Cu-l for $24 \mathrm{~h}$; whole-cell lysates were separated by SDS-PAGE and then reacted with indicated antibodies 

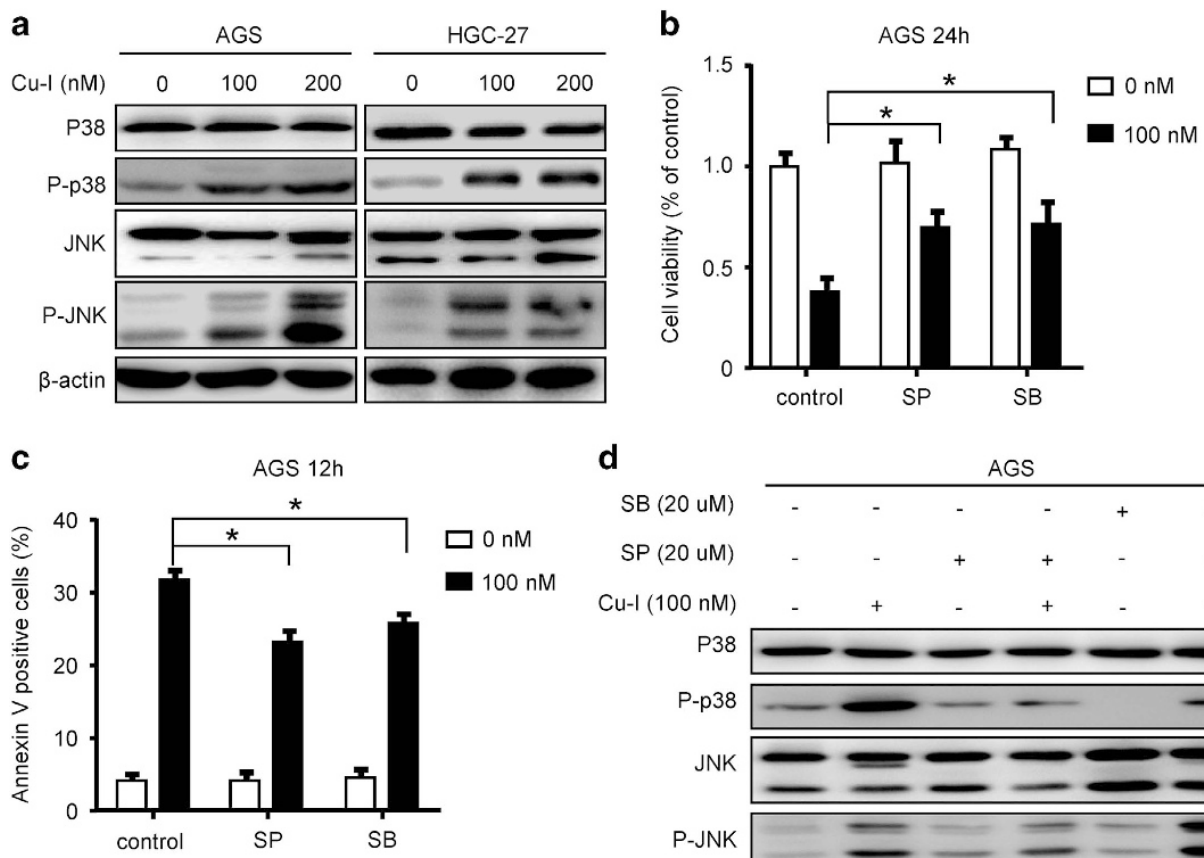

d

SB (20 uM)

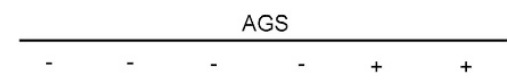

SP (20 uM)

Cu-I (100 nM)

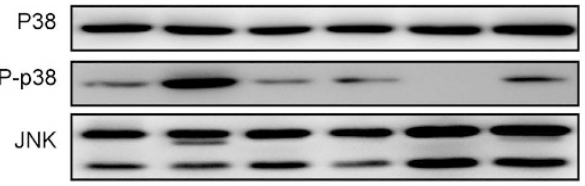

P-JNK

PARP

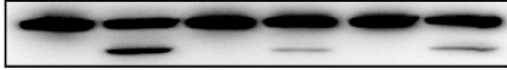

Cleaved caspase-3 (19KDa)

(17KDa)

Cdc2

CyclinB1

$\beta$-actin

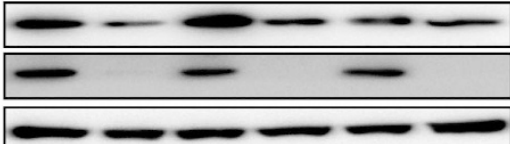

Figure 4 Cu-l induces JNK/p38 MAPK activation in gastric cancer cells. (a) Western blotting analysis of total and phosphorylated p38 and JNK in AGS and HGC-27 cells after treatment with 0-200 nM of Cu-l for $24 \mathrm{~h}$. (b-d) AGS cells were pretreated with the JNK inhibitor (SP600125, $20 \mu \mathrm{M}$ ) or p38 MAPK inhibitor (SB203580, $20 \mu \mathrm{M}$ ) for $1 \mathrm{~h}$, and then treated with $100 \mathrm{nM} \mathrm{Cu-I.} \mathrm{(b)} \mathrm{After} \mathrm{treatment} \mathrm{for} 24 \mathrm{~h}$, the cell viability was assayed by CCK-8. (c) After treatment for $12 \mathrm{~h}$, the percentage of apoptosis in treated AGS cells was assayed. Each data were shown as mean \pm S.D. of at least three independent experiments done in triplicates. ${ }^{*} P<0.05$, compared with Cu-l alone-treated group. (d) After treatment for $24 \mathrm{~h}$, western blot analysis of cell lysates was performed using indicated antibodies

major MAPK pathways in both cell lines exposed to Cu-I for $24 \mathrm{~h}$. There was a considerable JNK and p38 activation as evidenced by the increased phosphorylation of JNK and p38 proteins in both cell lines (Figure 4a). Pretreatment of AGS cells with SP600125 (JNK inhibitor) or SB203580 (p38 inhibitor) partly reversed Cu-I-inhibited cell viability (Figure 4b) by reducing the resultant apoptosis (Figure 4c). Consistently, caspase-3/PARP activation was also partly inhibited in cells pretreated with JNK or p38 inhibitor. However, there was no evident change in expression of the cell cycle regulators cyclin B1 and CDC2 (Figure 4d). This result suggests that JNK and p38 activation in gastric cancer cells following $\mathrm{Cu}-\mathrm{I}$ treatment inhibits cell viability mainly by inducing apoptotic cell death.

GADD45a forms a positive feedback loop with JNK/p38 MAPK to mediate gastric cancer cell apoptosis and is driven by decreased intracellular GSH/GSSG ratio regulated by NRF2 pathway. Previous report showed that GADD45a elicits its function through activation of the stress-induced JNK and p38 kinases, which contribute to increase in apoptosis and senescence. ${ }^{15}$ Consistently, in
AGS cells where GADD45a gene was silenced by using siRNA, p38 and JNK activation induced by $\mathrm{Cu}-\mathrm{I}$ was efficiently inhibited (Figure 5a). This observation, in combination with the partially attenuated caspase-3 and PARP cleavage (Figure 2i), suggests that the tumor-suppressive function of GADD45a is partly mediated by JNK and p38 activation, which in turn resulted in apoptosis of gastric cancer cells. Conversely, both JNK and p38 MAPK signaling may positively regulate GADD45a in various cell types. ${ }^{19,20}$ In agreement with the findings in other cells, pretreatment of gastric cancer cells with JNK inhibitor abolished the resultant induction of GADD45a by $\mathrm{Cu}-\mathrm{I}$, and pretreatment with p38 inhibitor notably decreased the GADD45a expression, although its induction by $\mathrm{Cu}$-I still existed (Figure $5 \mathrm{~b}$ ). These findings, together with the compromised apoptosis led by respective inhibitor (Figures $4 \mathrm{c}$ and $\mathrm{d}$ ), indicate that JNK and p38 MAPK signaling was involved in the induction of GADD45a and apoptosis by $\mathrm{Cu}-\mathrm{I}$ in gastric cancer cells. We then speculated that GADD45a acts in a positive feedback loop with JNK/p38 MAPK to mediate gastric cancer cell apoptosis led by $\mathrm{Cu}-\mathrm{I}$. 
Both GADD45a and MAPK can be modulated by reactive oxygen species (ROS) formation, ${ }^{21,22}$ which can be induced by Cu-I. ${ }^{18,23}$ To decipher whether ROS was involved in the antitumor activities of $\mathrm{Cu}-\mathrm{I}$, we assessed ROS levels by determining the mean fluorescence intensity of dichlorofluorescein (DCF) with the redox-sensitive probe 2'-7'-dichlorofluorescein diacetate (DCF-DA) in HGC-27 cells after exposure to $\mathrm{Cu}-\mathrm{I}$ for 30 and $60 \mathrm{~min}$, respectively. There was no significant increase of ROS in cells treated with $\mathrm{Cu}$-I (either $100 \mathrm{nM}$ or $200 \mathrm{nM}$ ) (Figure 5c). We failed to find a marked increase of ROS accumulation in HGC-27 or AGS cells even treated by $\mathrm{Cu}-\mathrm{I}$ for $6 \mathrm{~h}$ (Figure $5 \mathrm{~d}$ and Supplementary Figure $3 a$ ). Mitochondria are considered to be a major source of ROS. To further rule out the involvement of ROS, MitoSOXbased measurement using flow cytometry was employed to measure superoxide production in the mitochondrial matrix. The data revealed no significant increase of mitochondrial superoxide in AGS or HGC-27 cells treated by $\mathrm{Cu}-\mathrm{I}$ for $6 \mathrm{~h}$ (Supplementary Figure $3 b$ ). There is a balance between ROS and antioxidant systems, which is essential for cell survival. Cellular antioxidant systems are mainly controlled by GSH system that scavenges intracellular ROS to prevent cell death induced by stress or drugs. ${ }^{24}$ We then determined whether $\mathrm{Cu}-\mathrm{I}$ could change the redox status of cells. Levels of GSH and GSSG in HGC-27 cells following treatment with $\mathrm{Cu}-\mathrm{I}$ for $1 \mathrm{~h}$ were measured. As shown in Figure 5e, Cu-I remarkably reduced GSH levels but increased GSSG levels in HGC-27 cells in a dose-dependent manner. The intracellular GSH/GSSG ratio, an indicator of overall redox environment of cells, was consequently decreased (Supplementary Figure 3c). Co-treatment with $\mathrm{N}$-acetyl-L-cysteine (NAC), a substrate for synthesis of $\mathrm{GSH},{ }^{25}$ or exogenous $\mathrm{GSH}$, nearly completely eliminated $\mathrm{Cu}$-l-induced growth inhibition in both cell lines (Figure $5 f$ and Supplementary Figure 3d). Concordantly, colony-formation assay showed the difference of the colony size and number between AGS cells untreated and treated by Cu-I was nearly abolished by co-treatment with NAC (Supplementary Figure 3e). Moreover, the induction of GADD45 $a$ by $\mathrm{Cu}$-I was completely blocked by NAC in both cell lines (Figure $5 \mathrm{~g}$ ). Similarly, the activation of JNK/p38 MAPK signaling and subsequent caspase-3/PARP cleavage was also repressed by NAC (Figure 5h). Altogether, these results suggest that the inhibitory effect of $\mathrm{Cu}-\mathrm{I}$ may be originally attributed to its capacity in modulating intracellular GSH/GSSG ratio instead of markedly increasing ROS.

To further explore the specific molecular target of $\mathrm{Cu}-\mathrm{I}$ in decreasing intracellular GSH/GSSG ratio, we analyzed the change of NRF2 pathway after Cu-I treatment in gastric cancer cells. NRF2 is the sole controller of the enzymes responsible for producing GSH. Targets of NRF2 such as glucose-6phosphate dehydrogenase (G6PD) and glutamate-cysteine ligase complex modifier subunit (GCLM) have prominent roles in promoting cancer cell survival by neutralizing the toxic effects of oxidative stress. GCLM is involved in the catalytic reaction of glutamate with cysteine, which is the rate-limiting step in GSH synthesis. G6PD is responsible for NADPH production, leading to subsequent GSH regeneration. ${ }^{10}$ Interestingly, we found that $\mathrm{Cu}-\mathrm{I}$ inhibits the expression of NRF2 at both mRNA and protein levels. In addition, the downstream targets responsible for GSH generation and regeneration, GCLM and G6PD, were also suppressed (Figure $5 \mathrm{i}$ and Supplementary Figure $3 \mathrm{f}$ ). Therefore, these data indicated that $\mathrm{Cu}-\mathrm{I}$ might be a potential inhibitor of NRF2 pathway to break the redox homeostasis of the gastric cancer cells.

Cu-I inhibits in vivo growth of subcutaneous xenograft tumors of human gastric cancer cells. We further investigated the effects of $\mathrm{Cu}-\mathrm{I}$ in gastric cancer cells in vivo. HGC-27 cells were subcutaneously implanted in nude mice, and the experimental mice were given $1 \mathrm{mg} / \mathrm{kg}$ of $\mathrm{Cu}-\mathrm{I}$ intraperitoneally daily. Growth of the tumors was significantly inhibited in the mice treated by Cu-I compared with that in control mice (Figure 6a). The overall tumor weight was also significantly reduced in the mice that received $\mathrm{Cu}-\mathrm{I}$ (Figure 6b). Consistent with the result obtained in cancer cell lines in vitro, the intracellular GSH levels (Supplementary Figure 4a), and GSH/GSSG ratio (Figure 6c) in Cu-l-treated tumors were substantially reduced relative to the control tumors, whereas the overall GSSG levels were similar between $\mathrm{Cu}$-I-treated and control tumors (Supplementary Figure 4b). Cu-I failed to induce a significant increase of ROS production in Cu-l-treated tumors (Figure 6d). Furthermore, $\mathrm{Cu}$-I-treated tumors displayed significantly less-proliferative cells as determined by Ki-67 staining, and increased cell apoptosis as determined by TUNEL assay (Figure 6e, left, and middle). Moreover, immunohistochemical staining confirmed increase of GADD45a in Cu-l-treated tumors (Figure 6e, right). Finally, treatment with $\mathrm{Cu}-\mathrm{I}$ was without apparent ill consequences for the mice such as altered weight (Supplementary Figure 4c), toxicity in the lung, liver, spleen and kidney (Supplementary Figure 4d), signs of discomfort, or impaired movement (data not shown). These data strongly support $\mathrm{Cu}-\mathrm{I}$ as a promising therapeutic agent against human gastric cancer without apparent side-effects.

\section{Discussion}

Cellular redox homeostasis was identified to have a central role in a multitude of physiological and pathophysiological processes. ${ }^{26}$ Redox balance is achieved by various enzyme systems that neutralize toxic oxidants, such as ROS, which causes dysfunction of antioxidant defense mechanism in gastric mucosal, leading to DNA damage, accelerating cell death including apoptosis and subsequent cell proliferation, and therefore leading to the pathogenesis of gastric disorders as well as carcinogenesis. ${ }^{27}$ On the other hand, GSH has indispensable roles in cellular redox homeostasis by promoting ROS clearance, whereas GSH deficiency leads to oxidative stress. ${ }^{28}$ Recently, extensive work has been conducted and led to a multitude of new anticancer therapeutic agents, which increase the levels of ROS and/or suppress the antioxidant systems. ${ }^{25,29,30}$ Thus, modulating the redox homeostasis represents a promising target in gastric cancer treatment.

It's reported that $\mathrm{Cu}-\mathrm{I}$ exerts antitumorigenic activity by a ROS-mediated mechanism without inhibiting STAT3, ${ }^{18,23}$ suggesting targeting the redox homeostasis may be an alternative mechanism of action for $\mathrm{Cu}-\mathrm{I}$ in killing the cancer cells. In the present study, we show that $\mathrm{Cu}-\mathrm{I}$ markedly inhibits 
gastric cancer cell growth by inducing G2/M phase cell cycle arrest and apoptosis at low nanomolar concentrations. The mechanistic study revealed that the effect of $\mathrm{Cu}-\mathrm{I}$ is STAT3-independent. Our data further indicate that $\mathrm{Cu}$-I elicits tumor-suppressive activity via a relative decrease in $\mathrm{GSH}$ content and, to a lesser extent, an increase of the GSSG content, which subsequently leads to a pro-oxidizing shift in the GSH/GSSG ratio. Our findings, however, disagree with Zhang et al. ${ }^{18}$ who suggested that ROS generation has an essential role in Cu-l-induced autophagy and cell death in

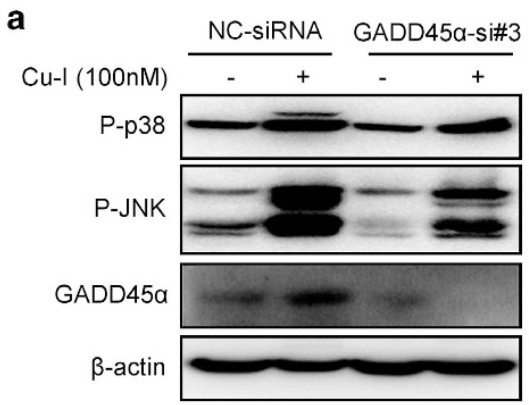

d

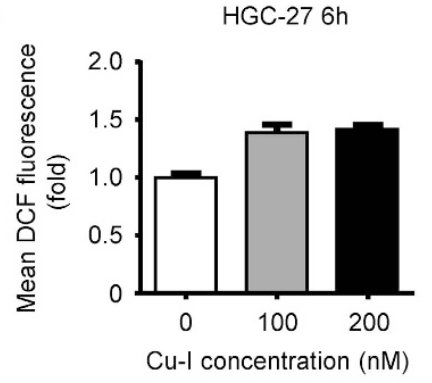

b

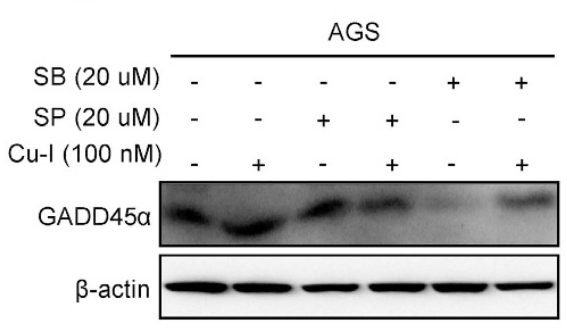

e

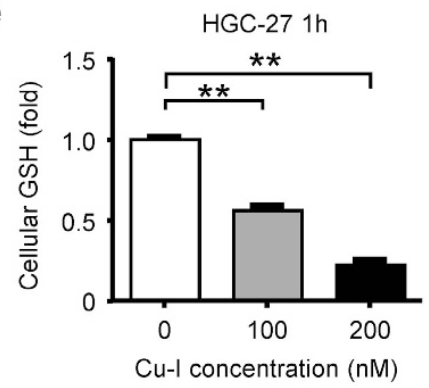

c
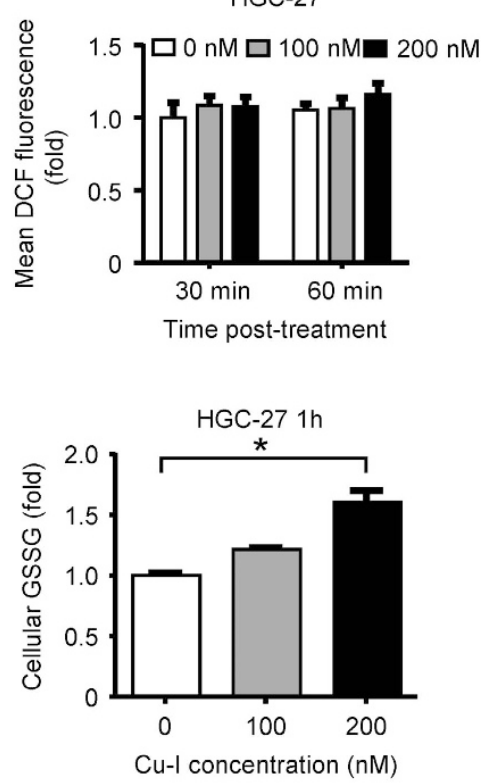

f

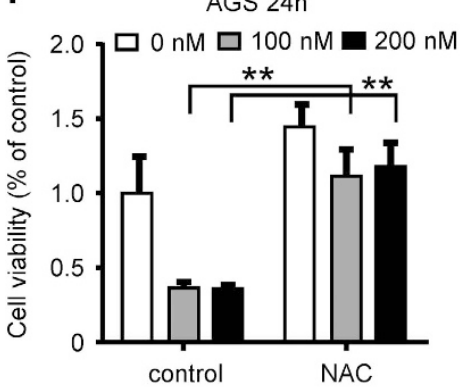

h

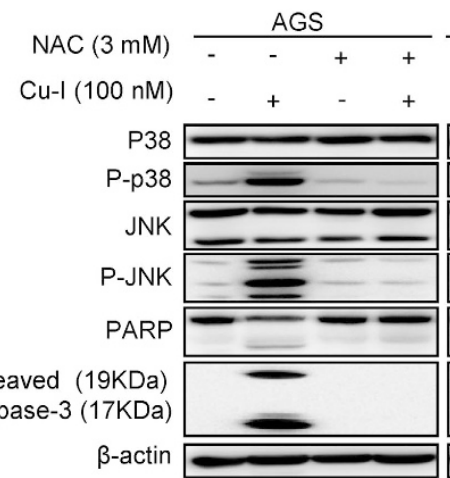

AGS 24h

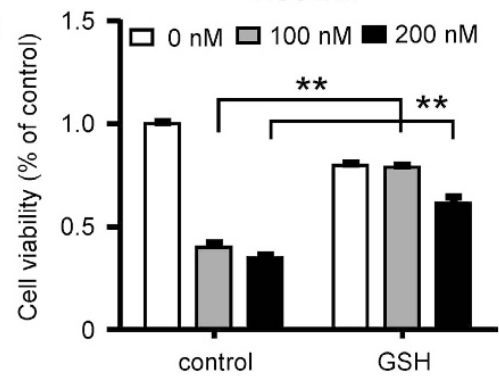

g

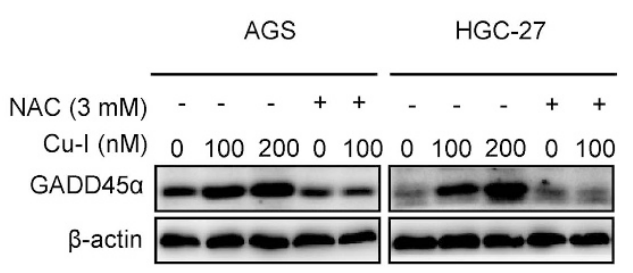

i
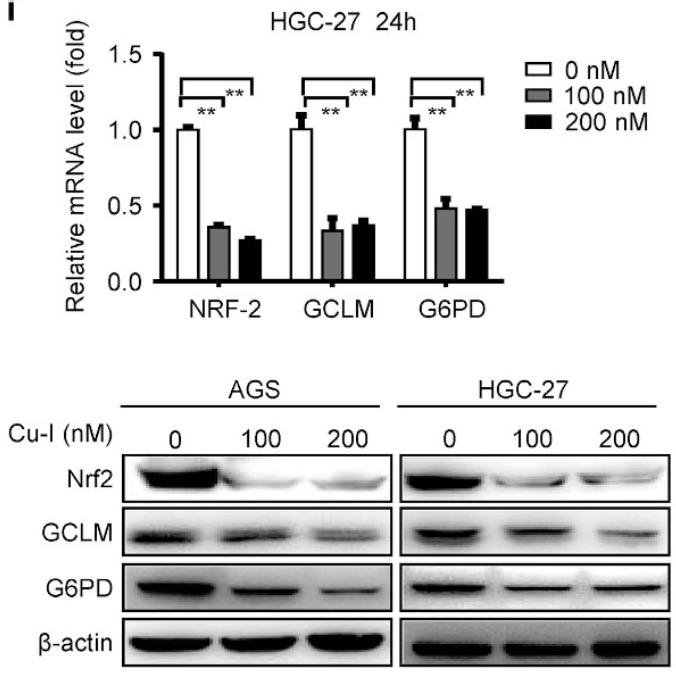
HeLa cells. This apparent discrepancy may be explained by the fact that the basal levels of ROS in AGS and HGC-27 cells were $>20$ times and 10 times higher than that in HeLa cells, respectively (data not shown). We found a 1.3- or 1.4-fold increase of ROS accumulation in AGS or HGC-27 cells followed by $\mathrm{Cu}-\mathrm{I}$ treatment for $6 \mathrm{~h}$. Given the high basal ROS levels and impaired antioxidant capacity, such a marginal increase of ROS accumulation would also efficiently kill the gastric cancer cells. NRF2 and its downstream targets such as GCLM and G6PD are reported to be the most important regulator of GSH production. ${ }^{10}$ Our study, to the best of our knowledge, revealed for the first time that $\mathrm{Cu}$-I could effectively inhibit the expression of NRF2 and its downstream targets GCLM and G6PD. The role of NRF2 in tumorigenesis has been identified in a broad spectrum of tumor types, such as ovarian, lung, breast, skin, and esophageal cancer. ${ }^{31}$ Some natural compounds, such as alkaloid trigonelline, which renders pancreatic cancer cells more susceptible to apoptosis, have been identified as NRF2 inhibitors. ${ }^{32}$ Our data suggest that $\mathrm{Cu}-\mathrm{I}$ might be a novel inhibitor of the NRF2 pathway. The underlying mechanism by which $\mathrm{Cu}$-I suppresses the NRF2 pathway in gastric cancer cells, however, remains unclear and will be investigated in our continued work.

GADD45 $a$ is a well-known p53-responsive stress protein to repair DNA damage, induce G2/M cell cycle arrest and apoptosis in various cancer cells. ${ }^{14,33}$ However, the role of GADD45a in gastric cancer cells remains poorly understood. Our study demonstrates for the first time that $\mathrm{Cu}-\mathrm{I}$ induced GADD45a through a p53-independent manner and subsequently led to G2/M cell cycle arrest and apoptosis in gastric cancer cells. GADD45a mRNA is induced in HGC-27 cells instead of AGS after Cu-I treatment, suggesting GADD45a is induced by $\mathrm{Cu}-\mathrm{I}$ at multiple levels, either transcriptional or translational depending on the genetic context of cells. It has been proposed that $\mathrm{Cu}-\mathrm{I}$ induced a considerable activation of JNK, p38 MAPK, and extracellular signal-regulated kinase after treatment in HeLa cells. ${ }^{18}$ Our study consistently revealed that $\mathrm{Cu}-\mathrm{I}$ activated $\mathrm{JNK}$ and p38 MAPK in gastric cancer cells. Furthermore, our data collectively suggest the $\mathrm{Cu}$-I induced GADD45 $a$ and JNK/p38 MAPK signaling form a positive feedback loop and can be reciprocally regulated by each other. Finally, and most importantly, Cu-l-induced GADD45 $a$ and JNK/p38 MAPK signaling were nearly completely eliminated when the cells were pretreated with NAC. Thus, our data strongly support a role for the decreased GSH/GSSG ratio by $\mathrm{Cu}-\mathrm{I}$ in modulating this sophisticated loop (Figure 6f).
In the present study, we show for the first time that $\mathrm{Cu}-\mathrm{I}$ has profound antigastric cancer activity both in vitro and in vivo. Instead of inhibiting the STAT3 pathway, Cu-I at low nanomolar concentrations induces cell cycle arrest and apoptosis in gastric cancer cell lines by decreasing the GSH/GSSG ratio, increasing the expression of GADD45a independent of p53 gene status, and activating JNK/p38 MAPK signaling. Taken together, our study provides new insight into the molecular effects of $\mathrm{Cu}-\mathrm{I}$ in cancer treatment. Meanwhile, as dysregulation of redox balance that develops in cancer cells in response to increased pro-oxidants (ROS generation) and/or depletion of antioxidants serves as one important therapeutic target for the rational design of new anticancer agents, ${ }^{34,35}$ our study provides a rationale for the development of $\mathrm{Cu}-\mathrm{I}$ as a novel therapeutic agent against human gastric cancer.

\begin{abstract}
Materials and Methods
Reagents, siRNAs, plasmids, and antibodies. Cu-I (C4493), N-acetylL-cysteine (NAC, A7250), DCF-DA (D6883), and L-Glutathione reduced (GSH, G4251) were purchased from Sigma-Aldrich (St. Louis, MO, USA). SP600125 (S1460), Z-VAD-FMK (S7023), and SB203580 (S1076) were purchased from Selleck Chemicals (Houston, TX, USA). DNA Damage Detection Kit was purchased from KeyGEN (KGA240). MitoSOX (M36008), SiRNAs target STAT3, and GADD45 $\alpha$ as well as a negative control siRNA (sequences are detailed in Supplementary Table 1) were purchased from Invitrogen (Carlsbad, CA, USA). P53-responsive element luciferase reporter (pp53-TA-luc, D2223) and the negative control reporter pGL6-TA (D2105) were purchased from Beyotime Biotechnology (Jiangsu, China). Anti-cyclin B1 (4138), anti-cdc2 (9116), anti-cdk7 (2916), anti-caspase-3 (9662), anticleaved caspase-3 (9664), anti-caspase-8 (9746), anti-caspase-9 (9502), anti-JNK (9258), anti- phospho-(Thr183/Tyr185)-JNK (4668), anti-p38 (8690), anti-phospho(Thr180/Tyr182)-p38 (4511), anti-STAT3 (9132), anti-phospho-(Tyr705)-STAT3 (9145), anti- phospho-(Ser15)-p53 (9286), and anti-phospho-(Ser139)-Histone H2AX (9718) antibodies were from Cell Signaling Technology (Beverly, MA, USA). Anti-GCLM (ab124827) and anti- Glucose 6 Phosphate Dehydrogenase (ab133525) were from Abcam (Cambridge, UK). Anti-phospho-(Tyr727)-STAT3 (P40763) antibody was from Bioworld Technology (St. Louis Park, MN, USA). AntiPARP (sc-7150), anti-p53 (sc-6243), anti-p21 (sc- 397), anti-puma (sc-28226), antiGADD45 $\alpha$ (sc-797), and anti-NRF2 (sc-722) antibody were from Santa Cruz Technology (Santa Cruz, CA, USA). Anti- $\beta$-actin (A5441) antibody was from SigmaAldrich.
\end{abstract}

Cell culture. The human normal gastric epithelial cell line GES-1, and gastric cancer cell lines AGS (p53-wild type) and HGC-27 (p53-mutated) were purchased from the cell bank of Chinese Academy of Sciences, and were authenticated by China Center for Type Culture Collection (CCTCC). All cell lines were cultured in RPMI- 1640 medium supplemented with $10 \%$ FBS in a humidified incubator at $37^{\circ} \mathrm{C}$ with $5 \% \mathrm{CO}_{2}$.

Cell viability assay. Cell viability was detected by CCK- 8 assay. Cells were seeded into 96 -well plates at $5 \times 10^{3}$ cells/well and cultured overnight at $37^{\circ} \mathrm{C}$. After treatment with $0.1 \%$ DMSO as control or Cu-I at varying concentrations for indicated

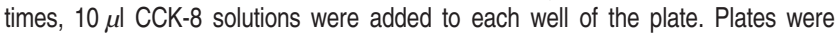

Figure 5 GADD45 $\alpha$ forms a positive feedback loop with JNK/p38 MAPK to mediate gastric cancer cell apoptosis and is driven by decreased intracellular GSH/GSSG ratio regulated by NRF2 pathway. (a) AGS cells were transfected as described in Figure 2i, and then treated with $100 \mathrm{nM} \mathrm{Cu}-\mathrm{I}$ for $24 \mathrm{~h}$, cell lysates were collected for western blot analysis with indicated antibodies. (b) AGS cells were treated as described in Figure 4d. The expression levels of GADD45 $\alpha$ protein were measured by western blotting. (c, d) HGC-27 cells were treated by Cu-I (0-200 nM) for various times, as indicated. The redox-sensitive probe 2' - $7^{\prime}$-dichlorofluorescein diacetate (DCF-DA, $5 \mu$ M) was incubated for 30 min after treatment. Fluorescence intensity was measured immediately after incubation by fluorescence microplate assay in 96 -well plates (c) or by flow cytometry analysis (d). Bars represent S.D. from three independent experiments performed in triplicates. (e) GSH and GSSG levels were evaluated in HGC-27 cells treated by Cu-I for $1 \mathrm{~h}$. Bars represent S.D. of three independent experiments performed in triplicates. ${ }^{*} P<0.05$, ${ }^{*} P<0.01$. (f) After pretreatment with $3 \mathrm{mM}$ NAC or $4 \mathrm{mM}$ GSH for $1 \mathrm{~h}$, AGS cells were then incubated with indicated concentrations of $\mathrm{Cu}-\mathrm{I}$ for $24 \mathrm{~h}$. Cell viability was determined by CCK-8. ${ }^{* *} P<0.01$, compared with Cu-I alone-treated group. (g, h) AGS and HGC-27 were pretreated with $3 \mathrm{mM} \mathrm{NAC}$, then treated with indicated concentrations of $\mathrm{Cu}-\mathrm{I}$ for $24 \mathrm{~h}$. Protein levels of GADD45 $\alpha$ (g) and JNK/p38 as well as subsequent caspase-3/PARP activation were verified by western blotting (h). (i) NRF2, GCLM, and G6PD mRNA levels in HGC-27 cells (top) treated by Cu-I for 24 h were assayed by real-time PCR. $\beta$-actin served as an internal control. ${ }^{\star *} P<0.01$. (bottom) the protein expression levels of NRF2, GCLM, and G6PD in AGS and HGC-27 cells treated by Cu-I for $24 \mathrm{~h}$ 

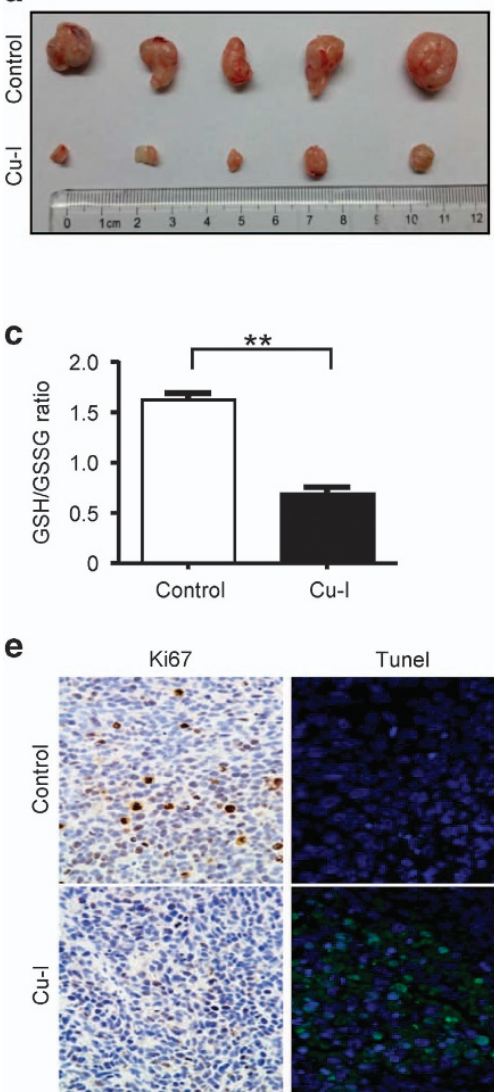

$400 \times$

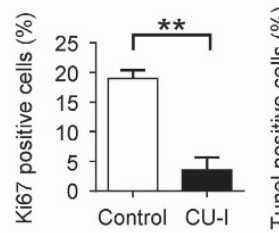

Cu-I

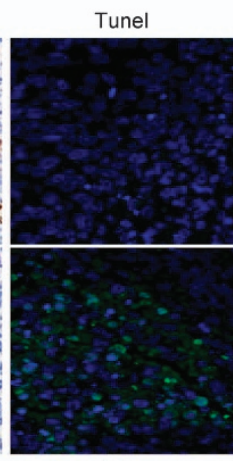

$400 \times$

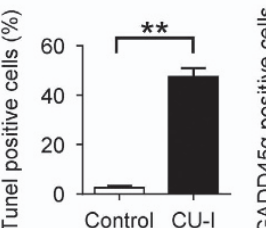

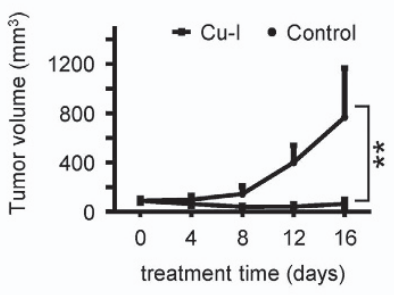

d

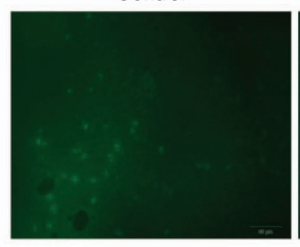

GADD45a
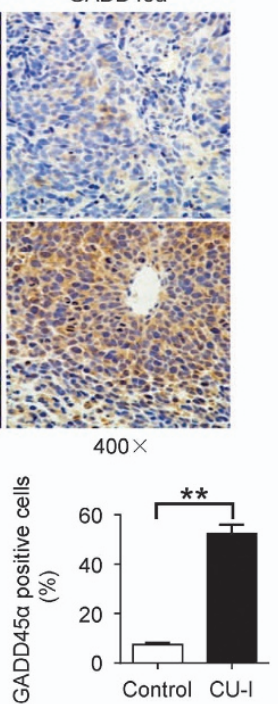

f b

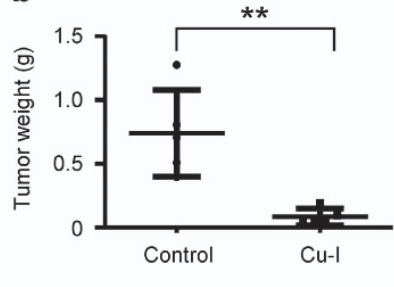

u-I
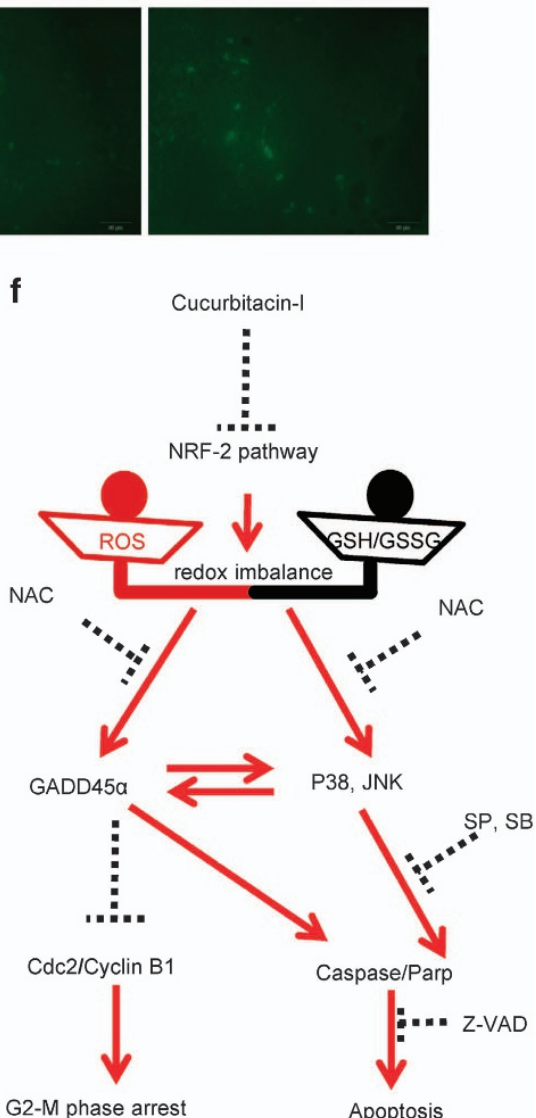

G2-M phase arrest

Apoptosis

Figure 6 Cu-l inhibits in vivo growth of subcutaneous xenograft tumors of human gastric cancer cells. (a) Left, resected tumors from each group $(n=5)$ were photographed. Right, increase of tumor volumes was plotted. (b) Tumor weight in each group was recorded. ${ }^{* *} P<0.01$. (c) Tumor lysates analysis of ratio of GSH/GSSG in each group. (d) Representative micrographs showing DCF fluorescence in resected tumors. (e) Representative immunohistochemistry, immunofluorescence micrographs, and quantitative data displayed as mean \pm S.D. showing ki67 (right), TUNEL (middle), and GADD45 $\alpha$ (left) staining, respectively (x400). (f) Schematic illustration of possible molecular mechanism of Cu-I-mediated cell growth inhibition in gastric cancer

incubated at $37^{\circ} \mathrm{C}$ for $1 \mathrm{~h}$, and then the absorbance at $450 \mathrm{~nm}$ was measured. All experiments were carried out in triplicate and repeated three times independently. The $\mathrm{IC}_{50}$ represented the drug concentrations leading to $50 \%$ cell growth inhibition and was calculated as described elsewhere. ${ }^{12}$

Cell cycle assay. About $3 \times 10^{5}$ cells/well were seeded in a six-well plate overnight at $37^{\circ} \mathrm{C}$, and then treated with indicated concentrations of $\mathrm{Cu}-\mathrm{l}$ for $12 \mathrm{~h}$. After harvesting the cells, cells were immediately stained according to the instructions of Cycle TEST DNA Reagent Kit (340242, BD Biosciences, San Jose, CA, USA). The phase of cell cycle was analyzed by flow cytometry (BD Biosciences, Aria II). Data were analyzed with BD FACSDiva Software. Al experiments were done in triplicate and repeated three times independently.

Apoptosis assay. Apoptosis induced by $\mathrm{Cu}-\mathrm{I}$ was assessed by flow cytometry using FITC Annexin V Apoptosis Detection Kit (556547, BD Biosciences). Similarly, cells were treated as done in the cell cycle assay. All operations were performed as previously described. ${ }^{12,36}$ All experiments were done in triplicate and repeated three times independently.

Colony-formation assay. Colony-formation assay was performed as previously described. ${ }^{37}$ In brief, $\sim 1 \times 10^{3}$ cells/well were seeded into six-well plates overnight and then incubated with indicated concentrations of Cu-I. After 14 days, the colonies were fixed with methanol and stained with crystal violet. Crystal violet stained colonies were photographed. All experiments were done in triplicate and repeated three times independently.

Western blotting. Cell lysates were collected as previously described. ${ }^{38}$ Thirty-microgram lysates were separated on $6-12 \%$ sodium dodecyl sulfatepolyacrylamide gels and transferred to PVDF membranes (Millipore, Bedford, MA, USA). TBST containing with $5 \%$ nonfat milk or bovine serum albumin was used to block nonspecific binding for $2 \mathrm{~h}$ at room temperature. Then membranes were incubated with primary antibodies according to the instructions overnight at $44^{\circ} \mathrm{C}$, 
followed by appropriate HRP-conjugated secondary antibodies (1:5000 dilutions). Signals generated by enhanced chemiluminescence (Millipore) were recorded with a CCD camera (CLINX, Shanghai, USA). Data are representative of at least three independent experiments.

RNA Extraction, reverse transcription, and Real-time PCR. Total RNA was extracted and reversely transcribed to CDNA as described previously. ${ }^{38}$ Real-time quantitive PCR assays was conducted using the SYBR Premix Ex TaqTM II kit (TaKaRa, Shuzo Co., Ltd., Kyoto, Japan). The real-time PCR experiments were performed with ABI PRISM 7500 Fast Real-Time PCR System. Primers used in real-time PCR experiments were shown in Supplementary Table 2.

Transfection of AGS cell with siRNA. Transfection was carried out using Lipofectamine RNAiMax Reagent (Invitrogen) as described elsewhere (reverse transfection method). ${ }^{39}$ In brief, $50 \mathrm{pmol}$ siRNA and $0.5 \mathrm{ml}$ Opti-MEM I Medium (Invitrogen) without serum was mixed in each well of six-well plate. Then $7.5 \mu \mathrm{l}$ of Lipofectamine RNAiMAX reagent was added and gently mixed. After incubation for $20 \mathrm{~min}$ at room temperature, $2 \mathrm{ml}$ of cell suspension including $3 \times 10^{5}$ cells in complete growth medium without antibiotics was added into each well. This gives a final siRNA concentration of $20 \mathrm{nM}$.

DNA transfection and luciferase reporter assay. DNA transfection and luciferase reporter assay were done as previously described. ${ }^{37}$ Cells were plated to 24-well plates $24 \mathrm{~h}$ prior to transfection experiments. Transfection experiment was carried out by adding $380 \mathrm{ng}$ of reporter plasmid along with a pRL-TK reporter plasmid $(20 \mathrm{ng})$ as a control for transfection efficiency. All assays were performed by using a Dual Luciferase Reporter Assay System (Promega, Madison, WI, USA).

ROS and glutathione assay. For analyses of cellular ROS, $5 \times 10^{3}$ cells or $3 \times 10^{5}$ cells/well were seeded in a 96-well plate or six-well plate, then treated by Cu-I (0-200 nM) as indicated time, respectively. The redox-sensitive probe DCF-DA $(5 \mu \mathrm{M})$ was incubated for $30 \mathrm{~min}$ after treatment. Fluorescence intensity was measured immediately by fluorescence microplate assay in 96-well plates as described ${ }^{40}$ or by flow cytometry analysis in six-well plates-treated cells. For highly selective detection of superoxide in the mitochondria of cells, Cu-I-treated cells were incubated with $5 \mu \mathrm{M}$ MitoSOX for $30 \mathrm{~min}$ in HBSS, washed twice with PBS and analyzed with flow cytometry (BD Biosciences, Aria II). ${ }^{18}$ For analyses of tissue ROS, tumors were frozen in optimum cutting temperature compound, cryosectioned, and incubated with $5 \mu \mathrm{M}$ DCF-labeled redox-sensitive probe for $90 \mathrm{~min}$ at $37^{\circ} \mathrm{C}$, and photographed with the same exposure time as described. ${ }^{41}$ The levels of GSH and GSSG were measured in cell or tumor lysates according to the instructions of GSH and GSSG Assay Kit (Beyotime Biotechnology, S0053). All experiments were done in triplicate and repeated three times independently.

Single-cell gel electrophoresis (SCGE comet assay). After $12 \mathrm{~h}$ or $24 \mathrm{~h}$ treatment, AGS cells were harvested and suspended in PBS for the SCGE comet assay, which was performed to determine the degree of DNA damage. All operations were performed as described in our previous study. ${ }^{42}$

Tumor xenograft model in nude mice. All animal procedures and care were approved by the Institutional Animal Care and Use Committee of Nanjing Drum Tower Hospital, Medical School of Nanjing University. HGC-27 cells $\left(\sim 3 \times 10^{6}\right.$ cells/mice) were resuspended in $100 \mu$ l serum-free medium and gently mixed with the same volume of ice-cold Matrigel, and were injected subcutaneously into the left flank of 4- to 6-week-old female BALB/c nu/nu nude mice $(n=10)$. Tumor size was measured as previously described. ${ }^{36}$ After 5 days when the tumor size reached $\sim 100 \mathrm{~mm}^{3}$, mice were randomly assigned into Cu-I treatment group (receiving $1 \mathrm{mg} / \mathrm{kg}$ of Cu-I in $5 \%$ DMSO in PBS by intraperitoneal injection daily, $n=5$ ) and control group (receiving vehicle containing the same percentage of DMSO in PBS, $n=5$ ). Tumor volume and animal weight were measured every 4 days. Mice were killed when control group tumors reached $\sim 1000 \mathrm{~mm}^{3}$. Tumors and organs including liver, spleen, lung, and kidney were harvested. All excised tumors were weighed, frozen in liquid nitrogen or fixed in 10\% neutral formalin and embedded in paraffin for further immunohistochemical or immunofluorescence studies.

Statistics. All experiments were repeated at least three times in triplicate. Each data is represented as mean \pm S.D. GraphPad Prism software v.6.01 with one-way analysis of variance (ANOVA) with Dunnett's multiple comparisons test and two-way
ANOVA with Tukey's multiple comparisons test was used in corresponding statistical evaluations ( ${ }^{*} P<0.05$; $\left.{ }^{* *} P<0.01\right)$.

\section{Conflict of Interest}

The authors declare no conflict of interest.

Acknowledgements. This study was supported by National Natural Science Foundation of China (No. 81401974, No.81472756, No.81272742, and No.81401977) and by Natural Science Foundation from the Department of Science \&Technology of Jiangsu Province (BK20140104).

1. Torre LA, Bray F, Siegel RL, Ferlay J, Lortet-Tieulent J, Jemal A. Global cancer statistics, 2012. CA Cancer J Clin 2015; 65: 87-108.

2. Wadhwa R, Song S, Lee JS, Yao Y, Wei Q, Ajani JA. Gastric cancer-molecular and clinical dimensions. Nat Rev Clin Oncol 2013; 10: 643-655.

3. Lordick F, Kang YK, Chung HC, Salman P, Oh SC, Bodoky G et al. Capecitabine and cisplatin with or without cetuximab for patients with previously untreated advanced gastric cancer (EXPAND): a randomised, open-label phase 3 trial. Lancet Oncol 2013; 14 : 490-499.

4. Blaskovich MA, Sun J, Cantor A, Turkson J, Jove R, Sebti SM. Discovery of JSI-124 (cucurbitacin I), a selective Janus kinase/signal transducer and activator of transcription 3 signaling pathway inhibitor with potent antitumor activity against human and murine cancer cells in mice. Cancer Res 2003: 63: 1270-1279.

5. Lui VW, Yau DM, Wong EY, Ng YK, Lau CP, Ho Y et al. Cucurbitacin I elicits anoikis sensitization, inhibits cellular invasion and in vivo tumor formation ability of nasopharyngeal carcinoma cells. Carcinogenesis 2009; 30: 2085-2094.

6. Chen YW, Chen KH, Huang PI, Chen YC, Chiou GY, Lo WL et al. Cucurbitacin I suppressed stem-like property and enhanced radiation-induced apoptosis in head and neck squamous carcinoma-derived CD44(+)ALDH1(+) cells. Mol Cancer Ther 2010; 9: 2879-2892.

7. Ishdorj G, Johnston JB, Gibson SB. Inhibition of constitutive activation of STAT3 by curcurbitacin-I (JSI-124) sensitized human B-leukemia cells to apoptosis. Mol Cancer Ther 2010; 9: 3302-3314.

8. Lo HW, Cao X, Zhu H, Ali-Osman F. Constitutively activated STAT3 frequently coexpresses with epidermal growth factor receptor in high-grade gliomas and targeting STAT3 sensitizes them to Iressa and alkylators. Clin Cancer Res 2008; 14: 6042-6054.

9. Hsu HS, Huang PI, Chang YL, Tzao C, Chen YW, Shih HC et al. Cucurbitacin I inhibits tumorigenic ability and enhances radiochemosensitivity in nonsmall cell lung cancer-derived CD133-positive cells. Cancer 2011; 117: 2970-2985.

10. Gorrini C, Harris IS, Mak TW. Modulation of oxidative stress as an anticancer strategy. Nat Rev Drug Discov 2013; 12: 931-947.

11. Ni Z, Lou W, Leman ES, Gao AC. Inhibition of constitutively activated Stat3 signaling pathway suppresses growth of prostate cancer cells. Cancer Res 2000; 60: 1225-1228.

12. Huang S, Chen M, Shen Y, Shen W, Guo H, Gao Q et al. Inhibition of activated Stat3 reverses drug resistance to chemotherapeutic agents in gastric cancer cells. Cancer Lett 2012; 315: 198-205.

13. Kanda N, Seno H, Konda Y, Marusawa H, Kanai M, Nakajima T et al. STAT3 is constitutively activated and supports cell survival in association with survivin expression in gastric cancer cells. Oncogene 2004; 23: 4921-4929.

14. Hildesheim J, Bulavin DV, Anver MR, Alvord WG, Hollander MC, Vardanian L et al. Gadd45a protects against UV irradiation-induced skin tumors, and promotes apoptosis and stress signaling via MAPK and p53. Cancer Res 2002; 62: 7305-7315.

15. Tront JS, Hoffman B, Liebermann DA. Gadd45a suppresses Ras-driven mammary tumorigenesis by activation of c-Jun NH2-terminal kinase and p38 stress signaling resulting in apoptosis and senescence. Cancer Res 2006; 66: 8448-8454.

16. Roos WP, Kaina B. DNA damage-induced cell death: from specific DNA lesions to the DNA damage response and apoptosis. Cancer Lett 2013; 332: 237-248.

17. Mah LJ, El-Osta A, Karagiannis TC. gammaH2AX: a sensitive molecular marker of DNA damage and repair. Leukemia 2010; 24: 679-686.

18. Zhang T, Li Y, Park KA, Byun HS, Won M, Jeon J et al. Cucurbitacin induces autophagy through mitochondrial ROS production which counteracts to limit caspase-dependent apoptosis. Autophagy 2012; 8: 559-576.

19. Park GB, Choi Y, Kim YS, Lee HK, Kim D, Hur DY. Silencing of PKCeta induces cycle arrest of EBV $(+)$ B lymphoma cells by upregulating expression of p38-MAPK/TAp73/ GADD45alpha and increases susceptibility to chemotherapeutic agents. Cancer Lett 2014; 350: 5-14.

20. Oh-Hashi K, Maruyama W, Isobe K. Peroxynitrite induces GADD34, 45, and 153 VIA p38 MAPK in human neuroblastoma SH-SY5Y cells. Free Radic Biol Med 2001; 30: 213-221.

21. Bickers DR, Athar M. Oxidative stress in the pathogenesis of skin disease. J Invest Dermatol 2006; 126: 2565-2575. 
22. Mates JM, Segura JA, Alonso FJ, Marquez J. Intracellular redox status and oxidative stress: implications for cell proliferation, apoptosis, and carcinogenesis. Arch Toxicol 2008; 82: 273-299.

23. Lopez-Haber C, Kazanietz MG. Cucurbitacin I inhibits Rac1 activation in breast cancer cells by a reactive oxygen species-mediated mechanism and independently of Janus tyrosine kinase 2 and P-Rex1. Mol Pharmacol 2013; 83: 1141-1154.

24. Ueda S, Masutani H, Nakamura H, Tanaka T, Ueno M, Yodoi J. Redox control of cell death. Antioxid Redox signal 2002; 4: 405-414.

25. Raj L, Ide T, Gurkar AU, Foley M, Schenone M, Li X et al. Selective killing of cancer cells by a small molecule targeting the stress response to ROS. Nature 2011; 475: 231-234.

26. Wang K, Zhang T, Dong Q, Nice EC, Huang C, Wei Y. Redox homeostasis: the linchpin in stem cell self-renewal and differentiation. Cell Death Dis 2013; 4: e537.

27. Suzuki H, Nishizawa T, Tsugawa H, Mogami S, Hibi T. Roles of oxidative stress in stomach disorders. J Clin Biochem Nutr 2012; 50: 35-39.

28. Li F, Han X, Wang R, Wang H, Gao Y, Wang $X$ et al. LKB1 inactivation elicits a redox imbalance to modulate non-small cell lung cancer plasticity and therapeutic response. Cancer Cell 2015; 27: 698-711.

29. Fang J, Seki T, Maeda H. Therapeutic strategies by modulating oxygen stress in cancer and inflammation. Adv Drug Deliv Rev 2009; 61: 290-302.

30. Trachootham D, Alexandre J, Huang P. Targeting cancer cells by ROS-mediated mechanisms: a radical therapeutic approach? Nat Rev Drug Discov 2009; 8: 579-591.

31. Kim YR, Oh JE, Kim MS, Kang MR, Park SW, Han JY et al. Oncogenic NRF2 mutations in squamous cell carcinomas of oesophagus and skin. J Pathol 2010; 220: 446-451.

32. Arlt A, Sebens S, Krebs S, Geismann C, Grossmann M, Kruse ML et al. Inhibition of the Nrf2 transcription factor by the alkaloid trigonelline renders pancreatic cancer cells more susceptible to apoptosis through decreased proteasomal gene expression and proteasome activity. Oncogene 2013; 32: 4825-4835.

33. Rosemary Siafakas A, Richardson DR. Growth arrest and DNA damage-45 alpha (GADD45alpha). Int J Biochem Cell Biol 2009; 41: 986-989.

34. Wondrak GT. Redox-directed cancer therapeutics: molecular mechanisms and opportunities. Antioxid Redox Signal 2009; 11: 3013-3069.

35. Noh J, Kwon B, Han E, Park M, Yang W, Cho W et al. Amplification of oxidative stress by a dual stimuli-responsive hybrid drug enhances cancer cell death. Nat Commun 2015; 6: 6907.
36. Ding X, Zhang B, Pei Q, Pan J, Huang S, Yang Y et al. Triptolide induces apoptotic cell death of human cholangiocarcinoma cells through inhibition of myeloid cell leukemia-1. BMC Cancer 2014; 14: 271.

37. Zhang B, Yang $Y$, Shi X, Liao W, Chen M, Cheng AS et al. Proton pump inhibitor pantoprazole abrogates adriamycin-resistant gastric cancer cell invasiveness via suppression of Akt/GSK-beta/beta-catenin signaling and epithelial-mesenchymal transition. Cancer Lett 2015; 356(2 Pt B): 704-712.

38. Zhang B, Chen J, Cheng AS, Ko BC. Depletion of sirtuin 1 (SIRT1) leads to epigenetic modifications of telomerase (TERT) gene in hepatocellular carcinoma cells. PLoS One 2014; 9: e84931.

39. Sousa JF, Nam KT, Petersen CP, Lee HJ, Yang HK, Kim WH et al. miR-30-HNF4gamma and miR-194-NR2F2 regulatory networks contribute to the upregulation of metaplasia markers in the stomach. Gut 2015; pii: gutjnl-2014-308759.

40. Kausar H, Munagala R, Bansal SS, Aqil F, Vadhanam MV, Gupta RC. Cucurbitacin B potently suppresses non-small-cell lung cancer growth: identification of intracellular thiols as critical targets. Cancer Lett 2013; 332: 35-45.

41. Sayin VI, Ibrahim MX, Larsson E, Nilsson JA, Lindahl P, Bergo MO. Antioxidants accelerate lung cancer progression in mice. Sci Transl Med 2014; 6: 221ra215.

42. Song $\mathrm{L}, \mathrm{Ma} \mathrm{L}$, Cong $\mathrm{F}$, Shen $\mathrm{X}$, Jing $\mathrm{P}$, Ying $\mathrm{X}$ et al. Radioprotective effects of genistein on HL-7702 cells via the inhibition of apoptosis and DNA damage. Cancer Lett 2015; 366: $100-111$.

cc) (i) Cell Death and Disease is an open-access journal published by Nature Publishing Group. This work is licensed under a Creative Commons Attribution 4.0 International License. The images or other third party material in this article are included in the article's Creative Commons license, unless indicated otherwise in the credit line; if the material is not included under the Creative Commons license, users will need to obtain permission from the license holder to reproduce the material. To view a copy of this license, visit http://creativecommons.org/licenses/by/4.0/ 